Review

\title{
Anticonvulsant potential of some medicinal plants and their beneficial properties
}

\author{
Mohammad Asif \\ Department of Pharmacy, GRD(PG)IMT, Dehradun, (U.K), 248009, India
}

\begin{abstract}
Epilepsy has now become the most serious brain disorder. A number of synthetic antiepileptic drugs are available in practice, however their effectiveness does not grip true with the entire population suffering from epilepsy. Traditional systems of medicine are popular in developing countries and most of the population relies on traditional medicines for their primary health care need. Medicinal plants to be an important source of traditional medicines. Various plants are used for the treatment of epilepsy in traditional system of medicines and various plants are yet to be scientifically investigated. Phytoconstituents have been the basis of treatment of human diseases including epilepsy. Herbal products are extensively used for the treatment of many diseases worldwide and where allopathic fails or has severe side effects. Psycho neural drugs are also have very serious side effects like physical dependence, tolerance, deterioration of cognitive function and effect on respiratory, digestive and immune system. So the treatments through herbal medicines are widely used across the world due to their wide applicability and therapeutic efficacy with least side effects, which in turn has accelerated the research regarding natural therapy. In this review we have summarized some herbal antiepileptics.
\end{abstract}

Keywords antiepileptics, convulsions, herbs, side effects

\section{INTRODUCTION}

Epilepsy is a major neurological disorder and up to 5\% of the world population develops epilepsy in their lifetime. The current therapy of epilepsy with modern antiepileptic drugs is associated with side effects, dose-related and chronic toxicity, as well as teratogenic effects, and approximately $30 \%$ of the patients continue to have seizures with current antiepileptic drugs therapy (Devinsky, 1995; Holmes, 1993; Mattson, 1995; Smith and Bleck, 1991). Epilepsy can affect all ages (Hauser and Annegers, 1993; Hauser et al., 1991). It is probable that the prevalence is higher in less developed countries because of higher incidence of antecedent factors such as brain infections, cranial and perinatal traumas and parasitic infections. Although the prognosis for controlling of seizures in most patients in terms of seizure control, remission and withdrawal of medication (Cockerel et al., 1993). Epilepsy is characterized by recurrent episodes of seizures. A seizure is due to abnormal discharge of some neurons in the brain. Antiepileptic drugs may have a stabilizing influence on neuronal membrane; prevent detonation of normal brain cells by the focal discharge, these drugs act only on those neurons which are firing repeatedly. Some drugs reduce low threshold $\mathrm{Ca}^{2+}$ current and abolish absence seizures whereas some drugs increase GABA activity in the synapse causing neuronal inhibition hence antiseizure effect. Glutamic acid causes increased synaptic transmission. A variety of glutamic acid receptors is NMDA receptors and reduction of NMDA receptor activity reduces seizure

\footnotetext{
${ }^{*}$ Correspondence: Mohammad Asif

E-mail: aasif321@gmail.com

Received May 3, 2013; Accepted November 8, 2013; Published

November 30, 2013

doi: http://dx.doi.org/10.5667/tang.2013.0012

C 2013 by Association of Humanitas Medicine
}

development (Manna et al., 2005). All the currently-available antiepileptic drugs are synthetic. Medicinal plants used for the therapy of epilepsy in traditional medicine (TM) have been shown to possess promising anticonvulsant activities and can be invaluable source of new antiepileptic drugs (Kabir et al., 2005; Sridharan, 2002; WHO, 2001). Many people in developing countries may not receive basic treatment due to high cost, unavailability and untoward effects associated with the available antiepileptic drugs. Therefore, many people in the developing countries still rely on TM for their basic health care needs. WHO encourages the addition of herbal medicines of proven safety and efficacy in the healthcare programs of developing countries (Amos et al., 2001). Scientific research is needed to provide evidences of the safety and efficacy of beneficial medicinal plants. Thus a need arises for new agents with greater efficacy, negligible or reduced side effects and devoid of unfavourable drug interactions unlike most antiepileptic drugs in the market today.

Anti convulsants: Epilepsy is a collective term used for a group of chronic seizure disorders having in common, sudden and transient episodes (seizures) of loss or disturbance of consciousness, usually but not always with a characteristic body movements (convulsions) and sometimes with autonomic hyperactivity. Epilepsy can be classified into two major groups.

1. Tonic clonic seizures/Grandmal/Major epilepsy: This is characterized by sudden loss of consciousness, followed by generalized tonic, followed by clonic convulsive movements. This is followed by a period of headache, drowsiness, confusion and sleep. The attack may be accompanied by tongue biting, frothing at the mouth and in continence (French et al., 2004; Gerlach and Krajewski, 2010; Kwan and Sander, 2004).

2. Petit-mal/Absence seizure: It consists of sudden cessation of ongoing conscious activity without convulsive movement and without loss of postural control. The patient 
appears to go blank for one second to one minute, and may be associated with bilateral clonic motor activity such as eyelid blinking. John Hughlings Jackson postulated about a century ago that epileptic seizures were caused by "occasional, sudden, excessive, rapid local discharge of grey matter". Modern electrophysiology has amply confirmed this. The characteristic patho physiologic event in a seizure is believed to be paraxysomal depolarization shift of neuronal membrane potential and associated burst discharge. Excitatory neurotransmitters, such as aspartate and glutamate are thought to be involved in the initiation and spread of seizure discharges and the inhibitory transmitter gamma amino butyric acid (GABA) is believed to be responsible for termination of seizure activity. The underlying neuro chemical defect in epilepsy may be a functional impairment in the inhibitory GABA mechanism. For including convulsion commonly used techniques are:

1. Electrical stimulation of brain by maximal electro shock induced method (MES) in rats.

2. Chemical stimulation: Chemical commonly used is PTZ, PIC, BIC, INH etc.

Causes of epilepsy: Approximately $75 \%$ of all cases of epilepsy have no known cause. This is referred to as idiopathic epilepsy. The other $25 \%$ of cases may be due to trauma to the foetus during pregnancy or during birth, poisoning (lead poisoning, environmental contaminants), viral or bacterial infection (meningitis), alcohol or other drug abuse, head trauma (car accident or blow to the head), alteration in blood sugar levels, brain tumour, or stroke. In most cases, epilepsy is not inherited. However, a person may inherit a predisposition or tendency to have epilepsy if they are subjected to specific conditions. People who do not know the cause of their epilepsy often feel more anxiety about having the disorder. However, when the cause of epilepsy is unknown, the prognosis for epilepsy is not necessarily any worse.

How to Identify a Seizure: Seizures may have many different appearances, which can be difficult to recognize. Some of the following may be indications that a seizure is occurring. Look for and make note of particular patterns of behaviour if they occur too often to be attributed to chance.

-Day dreaming or short attention blackouts

-Sudden falls for no reason

-Lack of response for short periods of time

-Unusual sleepiness and/or irritability when awakened from sleep

-Rhythmic movements of the head (head nodding) or head dropping

-Rapid blinking or upward eye rolling

- Frequent unwarranted complaints from the child that things look, sound, taste, smell or Feel "funny" or different than they actually are

- Sudden bowing or bending movements by babies who are sitting down

-Sudden stomach pain followed by sleepiness or confusion

-Repeated movements or jerking movements that look out of place or unnatural

-Memory gaps

- A blank stare followed by repetitive, meaningless movements

-Dazed behaviour with the inability to communicate or talk for a brief period of time

-Bed wetting or waking with a bitten tongue for no apparent reason

-Lip smacking, chewing or swallowing

PREVALENCE OF EPILEPSY
Approximately 1 to $2 \%$ of all people have epilepsy. 70 to $80 \%$ of those with epilepsy develop it before the age of 18 years. Of these, $44 \%$ develop epilepsy before age 5 . There is a $10 \%$ lifetime risk of having at least 1 seizure. Depending on the type of seizure, 20 to $95 \%$ of individuals will go on to have more than 1 seizure, at which time they may be diagnosed as having epilepsy. Seizures are seen very frequently in the first 10 years of life. This may be due in part to the low seizure threshold of some children. As the child's brain matures, the seizure threshold rises, making the child more resistant to seizures. As a result, most people who develop seizures during childhood or adolescence tend to experience a reduction in the intensity and frequency of seizures as they approach adulthood.

\section{HERBS AND ANTICONVULSANT ACTIVITIES}

Anticonvulsant drugs are used to control the convulsions by inhibiting the discharge and then producing hypnosis. Although several anticonvulsant drugs are available to treat convulsion, the treatment of epilepsy is still far from adequate because of their side effects and drug interactions. Thus there is a need for new more effective anticonvulsant drugs for intractable convulsion. In recent years research on medicinal plants has attracted a lot of attention worldwide. However nature is a rich source of biological and chemical diversity and a number of plants have been used in TM remedies and some are used in epilepsy also. Herbal medicines are widely used globally due to their wide applicability and therapeutic efficacy with low adverse effects. Several medicinal plants have been studied for their anticonvulsant activity. The researchs have been done at molecular level and several significant phytochemicals have been isolated. The present review is aimed at collecting data on promising medicinal plants that have anticonvulsant activity. The article refers to several plants with anticonvulsant properties.

Artocarpus heterophyllus: The anticonvulsant activity of alcoholic extract of stems of Artocarpus heterophyllus Lam in mice. The plant has been used in the treatment of diseases related to the CNS as an antiepileptic drug in TM. Artocarpine, artocarpesine, artocarpetin, artocarpetin A, cycloheterophyllin and artonins $\mathrm{A}$ and $\mathrm{B}$ are prenylflavonoids present in $\mathrm{A}$. heterophyllus Lam. Phytochemical studies revealed the presence carbohydrates, flavonoids, tannins, saponins and triterpenoids in alcoholic extract of stems of A. heterophyllus. Anticonvulsant activity was evaluated in PTZ, STR, and MESinduced convulsion models. alcoholic extract of stems of Artocarpus heterophyllus significantly delayed the onset of PTZ and STR-induced clonic convulsions and duration of extensor phase in MES induced convulsions indicating that this extract possess anticonvulsant activity (Jawaid et al., 2011).

Argyreia speciosa: Argyreia speciosa is also known as Vridha daraka in Sanskrit and a one of the important plants used in indigenous system of medicine. The root is used as an alternative tonic and useful in the diseases of CNS. The anticonvulsant effect of A. speciosa showed against PTZ and MES-induced convulsions (Vyawahare and Bodhankar. 2009). Alchornea cordifolia: The extract of the leaves of Alchornea cordifolia (AC) is extensively used in ethnomedicine for ulcers, rheumatic pains, febrile convulsions and for increasing physical performance.The antianxiety and anticonvulsant activities of the aqueous leaf extract of Alchornea cordifolia were exhibited, which may support the use of A. cordifolia against anxiety or fatigue in ethnomedicine (Umukoro and Aladeokin, 2010).

Annona diversifolia: Annona diversifolia is consumed as fresh fruits, but, because of their effects on the CNS, also used in folk medicine. Hexane extract and palmitone exhibited anticonvulsant properties and delayed establishment of a 
kindling state (González-Trujano et al., 2009).

Apocynum venetum: The anxiolytic activity of an aqueous extract of Apocynum venetum L. (Apocynaceae) and its fractionation using the elevated plus maze (EPM) in mice as a model of anxiety. The anxiolytic activity of kaempferol was partially antagonized by concomitant administration of flumazenil, but not by WAY-100635 (Grundmann et al., 2009).

Albizzia lebbeck: The ethanolic extracts of leaves of Albizzia lebbeck have been shown to protect the mice from MES, electrical kindling and PTZ-induced convulsions. The activity lies in the methanolic fraction of chloroform soluble part of ethanolic extract of leaves (Kasture et al., 2002).

Benkara malabarica: The anticonvulsant activity of the Benkara malabarica plant extract is predominantly GABA mediated and may be due to the action of scopoletin alone or is a result of synergy of different compounds in the extract and scopoletin is the major constituent (Oraon et al., 2010).

Bryonia Laciniosa: Bryonia Laciniosa exhibited anticonvulsant activity against MES-induced seizure test. This plant also indicated that alcoholic extract showed antiasmatic and analgestic activity (Reddy et al., 2010).

Benincasa hispida: Benincasa hispida fruit is used as a vegetable in India and other tropical countries. A methanolic extract of B. hispida were using PTZ, STR, picrotoxin and MES model. The extract significantly inhibited the hind limb extension induced by MES and significantly increased the latency of convulsion and death induced by PTZ and STR respectively.

Butea Monosperma: The various functions of petroleum ether extract of Butea Monosperma were studied for its anticonvulsant activity and active constituent was found to be triterpene in the n-hexane ethyl acetate (1:1) fraction. This triterpene significantly inhibited seizure induced byMES, PTZ, electrical kindling and combination of lithium sulphate with pilocarpine nitrate while was not effective against STR and picrotoxin induced convulsions (Kasture et al., 2002).

Bramhi ghrita: The CNS activity of Bramhi ghrita in a polyherbal formulation that contained Bacopa monneri, Evolvulus alsinoids, Acorus calamus, Saussurea lappa and cow's ghee. The effect of B. ghrita on motor coordination, behavior, sleep, convulsions, locomotion and analgesia was evaluated. The formulation exhibited reduced alertness, spontaneous locomotor activity and reactivity. It also antagonized the behavioral effects of d-amphetamine, potentiated the pentobarbitone induced sleep and increased the pain threshold. B. ghrita protected mice from MES and PTZinduced convulsions. The B. ghrita was found to be a CNS depressant with anticonvulsant activity (Achliya, et al., 2005). B. monneri is a well-known nootropic plant having sedative tranquilising, memory-enhancing, antioxidant, and hepatoprotective effects (Fulzele et al., 2002; Sumathy et al., 2001). A. calamus is reported for its carminative activity, sedative and tranquilizing actions. S. lappa has been reported to possess antiulcer, anti-inflammatory, immunostimulant, antispasmodic, hypotensive and respiratory depressant actions (Chao et al., 2000; Kulkarni and Desai, 2001). E. alsinoids has been used traditionally as a brain tonic and sedative, anthelmintic, antiepileptic and against leucoderma (Kirtikar and Basu, 1998). An effect of B. ghrita on PTZ-induced and MESinduced seizures was studied in mice. Such effects are observed with antipsychotic agents. B. ghrita also showed antinociceptive action by tail flick method. BG inhibited MES and PTZ-induced convulsions in a dose-dependent manner. The anticonvulsant action of the formulation is mediated by the $\mathrm{Cl}^{+}$ channel of the GABA/benzodiazepine receptor complex. B. ghrita showed reduction in the tonic extensor phase in MES- induced seizures and slightly prolonged the onset of action in PTZ-induced convulsions (Achliya et al., 2004).

Cestrum nocturnum: The effect of n-butanol fraction of hydro alcoholic extracts of Cestrum nocturnum, against seizures induced by PTZ, MES-induced convulsion in mice. The different doses of hydro alcoholic extracts of C. nocturnum were subjected to PTZ and MES treatment. The latency to onset of convulsion was recorded in PTZ model and the duration of tonic hind limb extension was recorded in MES. In PTZ model the hydro alcoholic extracts of C. nocturnum showed significant delay in the onset of convulsion. In MES model showed significant decrease in the duration of hind limb extension in mice. In addition the brain GABA level was significantly increased by hydro alcoholic extracts of C. nocturnum. Thus anticonvulsant effect of hydro alcoholic extracts of C. nocturnum against PTZ, MES-induced convulsion in mice which maybe be due to GABAergic transmission (Jawaid et al., 2011).

Carissa carandas: Anticonvulsant effect of the ethanolic extract of the roots of Carissa carandas (ERCC) on MES and chemo induced seizures. The ethanolic extract of the roots of C. carandas was evaluated for its anticonvulsant effect on MES and PTZ, picrotoxin-, bicuculline- and $\mathrm{N}$-methyl-dl-aspartic acid-induced seizures in mice. The latency of tonic convulsions and the number of animals protected from tonic convulsions were noted. The ethanolic extract of the roots of C. carandas significantly reduced the duration of seizures induced by MES. The same doses also protected animals from PTZ-induced tonic seizures and significantly delayed the onset of tonic seizures produced by picrotoxin and N-methyl-dl-aspartic acid. The extract had no effect on bicuculline-induced seizures. The ethanolic root extract of C. carandas may produce its anticonvulsant effects via non-specific mechanisms since it reduced the duration of seizures produced by MES as well as delayed the latency of seizures produced by PTZ and picrotoxin (Jawaid et al., 2011).

Carissa carandas: Carissa carandas Linn. (Syn. Carissa congesta Wight) is an evergreen shrub with short stem and strong thorns in pairs (family Apocynaceae). The plant is native and common throughout much of India, Sri Lanka, Java, Malaysia, Myanmar and Pakistan. In TM, the plant is used as an anthelmintic, astringent, appetizer, antipyretic, in biliary, stomach disorders, rheumatism and disease of the brain. The extract of the plant possesses cardiotonic, antipyretic and antiviral activity. Various cardiac glycosides, a triterpenoidal constituent carissone and $\beta$-sitosterol were reported from the root extract of the plant.

Cyperus articulates: Cyperus articulatus is used in the TM in Africa and Latin America for various disorders of CNS including epilepsy. The methanolic extract of rhizomes was tested for its anticonvulsant action against PTZ, MES, STR and picrotoxin induced convulsions. The extract was effective in all models except in picrotoxin. Further studies suggest that the aqueous extract of $\mathrm{C}$. articulatus showed dose dependent reduction in spontaneous epileptic form discharge and NMDA induced depolarization in rat cortical wedge preparation at concentration at which L-amino-3-hydroxy-5methyl-isoxazole4-propionic acid (AMPA) induced depolarization are not affected. This indicates that the extract may contain components acting as AMPA antagonist responsible for the possible antiepileptic action (Ngo et al., 2001).

Crocus sativus: Stigma of Crocus sativus L is used in TM for its anticonvulsant property. The aqueous and ethanolic extracts delayed the onset of tonic convulsions in PTZ model while reduced the duration of tonic seizures in MES model, indicating partial protection against epilepsy and attributed to 
its reported generalized CNS depressant effect (Abe and Saito, 2000).

Cyperus rotundus: The ethanol extract of Cyperus rotundus significantly potentiated the sleeping time of mice induced by standard hypnotics, viz. pentobarbitone sodium, diazepam, and meprobamate in a dose dependent manner. It also potentiated analgesia induced by morphine and pethidine in mice. Pretreatment with ethanol extract of $\mathrm{C}$. rotundus caused significant protection against strychnine and leptazol induced convulsions (Pal et al., 2009).

Croton zambesicus: The ethanolic root extract of Croton zambesicus was protecting gastric mucosa against ulcers induced by indomethacin, ethanol and reserpine. The root extract significantly delayed the onset and latency of convulsion caused by PTZ and picrotoxin (Okokon et al., 2009).

Copaifera reticulate: Copaiba oil oleoresin exuded from Copaifera reticulata Ducke is mainly used as anti-inflammatory, healing and anti-tumoral folk medicines. The putative anxiolytic effect was shown by C. reticulata (Curio et al., 2009).

Capparis deciduas: Capparis decidua (frock) Edgew (family Capparidaceae) is a xerophytic shrub, known as karrel or ker, bark and shoot are used as analgesic, anti-inflammatory, hypolipidemic, and antidiabetic agents. The C. decidua has CNS depressant and anticonvulsant activities (Goyal et al., 2009).

Calotropis gigantean: The stem barks of Calotropis gigantea Linn. (Asclepiadaceae) is a widely growing plant with number of medicinal properties. The bark showed anticonvulsant effect against MES and PTZ induced seizure models and used traditionally in Indian system of medicine. The different extracts of stem barks showed anti-convulsant activity. The methanolic extract at $180 \mathrm{mg} / \mathrm{kg}$ body weight significantly inhibited the Hind Limb Tonic Extension (HLTE) induced by MES and onset of clonic convulsion or latency of convulsion induced by PTZ (Debnath et al., 2010).

Centella asiatica: The anticonvulsant effect of different extracts of Centella asiatica with respect to cholinergic activity on PTZ- induced seizures. Pretreatment with C. asiatica extracts caused recovery of the levels of acetylcholine and acetylcholinesterase. These findings suggest that $\mathrm{C}$. asiatica causes perceptible changes in the cholinergic system as one of the facets of its anticonvulsant activity (Visweswari et al., 2010).

Cymbopogon citrates: The fresh leaves of Cymbopogon citratus are a good source of an essential oil rich in citral, and its tea is largely used in the Brazilian folk medicine as a sedative. A similar source of essential oil is C. winterianus, rich in citronellal (Silva et al., 2010).

Carissa edulis: The anticonvulsant activity of the extract was assessed in PTZ-induced, MES induced convulsions, with benzodiazepine and phenytoin as standard drugs, respectively. The Carissa edulis possesses biologically active constituent(s) that have anticonvulsant activity which supports the ethnomedicinal claims of the use of the plant in the management of epilepsy (Ya'u et al., 2008).

Curcumin: Several experimental studies have reported neuroprotective and antioxidant activity of certain natural products like curcumin, an active ingredient of turmeric.The dose of $100 \mathrm{mg} / \mathrm{kg}$ on acute administration showed anxiogenic effect on elevated plus maze and actophotometer test. However, the anxiogenic effect of curcumin disappeared on chronic administration. The curcumin appears to possess anticonvulsant activity in mice (Bharal et al., 2008).

Calotropis gigantean: Calotropis gigantea Linn (Asclepiadaceae) a widely growing plant has been reported to possess number of medicinal properties. In the TM, the roots and barks of C. gigantea, are used as anticancer, antifertility, antidote for snakebite, antidiarrheal, antiscabetic, cardiovascular diseases and various skin diseases. Leaves are used in asthma, skin diseases like eczema; elephantiasis etc. juice is used in leprosy, syphilis and idiopathic ulceration etc. Traditionally roots and barks of C. gigantea are used for all kinds of fits, epilepsy, convulsions in children's and paralysis complaints. The plant is considered crude drugs of Bangladesh and medicinal plant of Indonesia. The new oxypregnaneoligoglycosides named, calotropins A and B have been isolated from the roots of C. gigantean and exhibited anticancer activity. The anti convulsant activity exhibited by different extracts of stem barks of C. gigantea Linn. against seizures induced by MES, PTZ model (Chitme and Ramesh, 2004).

Cochlospermum tintorium: Cochlospermum tintorium (Cochlospermaceae) and Paullinia pinnata (Sapindaceae) are widely used medicinal plants in Northern Nigeria in the management of epilepsy. The hydroalcoholic root bark extract of C. tintorium and methanolic stem bark extract of P. pinnata were investigated for anticonvulsant activities using MES, PTZ and STR-induced seizures. The P. pinnata extract produced a dose-dependent protections against MES while the C. tintorium extract did not protect the animals at the doses tested (5, 10 and $20 \mathrm{mg} / \mathrm{kg}$ ). The two extracts did not protect the animals against STR-induced seizure. Both extracts protected $20 \%$ of the animals against PTZ-induced seizure at the highest doses tested The aqueous methanolic stem bark extract of P. pinnata contains bioactive constituents that may be beneficial in grand mal epilepsy and lend pharmacological credence to the ethnomedical claim for the use of the plant in the management of this epilepsy (Maiha et al., 2009). The C. tinctorium and P. pinnata are commonly used medicinal plants in TM practice in Nigeria. C. tintorium (Cochlospermaceae) is a bushy plant attaining about $50 \mathrm{~cm}$ in height. Decoction of the leafy twigs is used in West Africa for jaundice, yellow fever and heart irregularities while the leaves decoction is used for diarrhoea, dysentery and colic (Burkill, 2000).

Citrus maximus: Citrus maximus (pomelo) family (Rutaceae) is the biggest of all citrus fruits; each fruit weighing from $0.5-1.4 \mathrm{~kg}$. Traditionally, various parts of the plant like the leaves, flowers, fruit pulp and the rind are being used in cough, dyspepsia, as stomachic, in urinary disorders and insomnia. The ethanolic extract of C. maximus leaves was evaluated by MES method and PTZ induced seizure models. The ethanolic extract of C. maximus leaves produced a dose dependent anticonvulsant activity in both MES and PTZ seizure models which was found to be highly significant. This showed potential anticonvulsant activity of C. maximus leaves for both grand-mal and petit-mal epilepsy.

Delphinium denudatum: Dried roots of Delphinium denudatum are a popular folk remedy for the treatment of epilepsy in TM. Anticonvulsant screening of ethanolic extract and aqueous fraction of the plant against MES, PTZ, BIC, picrotoxin and STR induced convulsions was carried out wherein. Ethanolic extract showed dose dependent anticonvulsant action on seizures induced by PTZ and BIC while aqueous extract showed activity against PTZ and MES induced convulsions especially inhibition of hind limb extension (Raza et al., 2001).

Eupatorium birmanicum: Various species of Eupatorium (Asteraceae) are used medicinally across Europe, America and Asia in various ailments as emetic, diuretic, purgative, diaphoretic, laxative and emmenagogue. The leaves of E. birmanicum is used TM in Manipur for treating various ailments like leucorrhoea, stomach ulcer and localized burning sensation on the skin. This significantly reduces the duration of 
tonic hind limb extension in MES and increases the latency of myoclonic spasm and clonic convulsion induced by PTZ ( $p<$ 0.001). The aqueous extract of E. birmanicum significantly protects against both MES and chemioshock.

Ferula gummosa Boiss: Ferula gummosa Boiss is a reputed drug in Iranian TM and has been used as antiepileptic remedy. The evaluation of seed acetone extract reported its anticonvulsant effect against PTZ and MES induced convulsions (Sayyah et al., 2002).

Ficus religiosa: In Ayurveda it is claimed that leaves of Ficus religiosa possesses anticonvulsant activity. The leaves extract of F. religiosa was evaluated for its anticonvulsant activity against PTZ induced convulsion. The study revealed 80 to $100 \%$ protection against PTZ induced convulsions. Nantenine, an amorphine alkaloid, found in several vegetal species is used in TM. A screening of anticonvulsant activity of different doses of nantenine using PTZ (100 mg/ kg) and MES models revealed its significant biphasic activity. It is found to be anticonvulsant at low doses $(20-50 \mathrm{mg} / \mathrm{kg}$ i.p) against both models while convulsant at higher doses (above $75 \mathrm{mg} / \mathrm{kg}$ ). The biphasic action of nantenine on $\mathrm{Na}^{+} \mathrm{K}^{+}$ATPase, suggested that convulsant effect appears to be related to inhibition of $\mathrm{Na}^{+} \mathrm{K}^{+}$ATPase at high doses while decrease in $\mathrm{Ca}^{2+}$ influx into the cell at low doses may be the reason for its anticonvulsant effect (Ribeiro and Leite, 2003).

Ferula species: Several Ferula (Umbelliferae) species have been used in Iranian TM as antiflatulent, antispasmodic, anticonvulsant, expectorant, etc. It also showed cytotoxicity and anticonvulsant activity. The oleo-gum resin of $\mathrm{F}$. assafoetida showed dose dependent cytotoxicity which was highest in F. badrakema fruits and lowest in F. badrakema roots (Bagheri et al., 2010).

Ficus religiosa: Ficus religiosa (Moraceae) is reported to have numerous therapeutic utility in folk medicie. Among different biological activities on CNS, it has been reported to be used in ethnomedical treatment of epilepsy. Extract showed no toxicity, potentiated pentobarbitone induced sleep and inhibited seizures induced by MES and picrotoxin in a dose dependent manner. Anticonvulsant effect of extract was comparable to clinically used antiepileptic drugs (phenytoin and diazepam). However, PTZ induced seizures were not inhibited. Animals pretreated with cyproheptadine showed inhibition of the anticonvulsant effect of extract (Singh and Goel, 2009).

Ferula gummosa: Ferula gummosa Boiss. (Apiaceae) is a perennial plant native to central Asia. In medicinal literatures, there are some reports regarding the anticonvulsant, antispasmodic, expectorant, antinociceptive and wound-healing activities. In Iranian TM, there are some reports regarding the anticonvulsant effect of $\mathrm{F}$. gummosa Boiss. Anticonvulsant activity, neurological insufficiency and lethality of the root acetone extract were exhibited dose-dependent prevention of tonic seizures induced by PTZ. However, the extract produced sedation and motor impairment (Sayyah et al., 2002).

Gingko nuts: Gingko nuts are commonly used in Japan and China. The occurrence of convulsions generalized after consumption of large amount of gingko nuts in the people without any past or family history of epilepsy. Patients develop vomiting and seizures about $4 \mathrm{~h}$ after ingestion (Miwa et al., 2001).

Glychrrhiza glabra: In the TM system, roots and rhizomes of Glychrrhiza glabra have been in use since centuries. Anticonvulsant action of its ethanolic extract of roots and rhizomes (Ambawade et al., 2002), the extract significantly and dose dependently delayed the onset of clonic convulsions induced by PTZ.

Guettarda speciosa: Guettarda speciosa Linn. (Family:
Rubiaceae) is widely distributed from East Africa to Asia. This plant is common along the seashore, sea cliffs, beach thickets and low land forests. In Fiji, the stem is used to promote menstruation and plant is used to treat maternal postpartum infections. A decoction of the leaves is used to treat coughs, colds and sore throats. The inner bark is used in the treatment for conjunctivitis. In Tuvalu, the leaves are used for poultices. In Tonga, a tea made from the inner bark is used to treat epilepsy. In Tahiti, the plant has antidiarrheic, febrifugal and anticholinergic applications. In around Tirunelveli District, India, have claimed that the inner barks are being traditionally used in epilepsy. This plant contains loganic acid and secologanin (Cambie and Ash, 1994). Antiepileptic activity of Guettarda speciosa (L.), ethanolic extract of inner bark used for acute toxicity test and screened for antiepileptic activity on MES and PTZ induced seizures models. There was significant delay in clonic seizure induced by PTZ and a dose-dependent decrease in duration of hind leg extensor phase in MES model after treatment with the extract. In MES model, it showed significant reduction in duration of hind leg extension with 200 $\mathrm{mg} / \mathrm{kg}$ dose and effect was dramatically reduced with $400 \mathrm{mg} / \mathrm{kg}$. Similar dose-dependent delays on the onset of clonic convulsions were obtained with PTZ (Arumugam et al., 2009).

Hypericum perforatum: Hypericum perforatum $\mathrm{L}$ is mentioned in Iranian TM for its anticonvulsant activity. The aqueous and ethanol extract of aerial part to scientifically evaluated the use of this plant. These extracts were tested against PTZ and MES induced convulsions. In PTZ, the extract delayed the onset of tonic convulsion and protected the mice against mortality while in MES model the result was not significant (Hosseinzadeh et al., 2005).

Hyscyamus niger: Effects of Hyscyamus niger L on central nervous system (CNS) have been known for many years. The anticonvulsant effects of methanolic extract of $\mathrm{H}$. niger $\mathrm{L}$. against picrotoxin induced was studied (Reza et al., 2009).

Lavandula stoechas: Lavandula stoechas $\mathrm{L}$ has been used for a long time in TM as an anticonvulsant. The hydromethanolic extract of L. stoechas flowers significantly reduced the severity and increased the latency of onset of convulsions induced by PTZ. Moreover, in isolated rabbit jejunum preparations, it caused a dose dependent $(0.1-1.0 \mathrm{mg} / \mathrm{ml})$ relaxation of spontaneous contraction and inhibited $\mathrm{K}+$ induced contractions thereby, suggesting $\mathrm{Ca}^{2+}$ channel blockade. Further, pretreatment of the jejunum preparation with L. Stoechas produced a dose dependent shift of the $\mathrm{Ca}^{2+}$ dose response curve to the right similar to the effect of standard $\mathrm{Ca}^{2+}$ channel blocking activity (Gilani et al., 2000).

Laurus nobilis linn: The essential oil of leaf of Laurus nobilis linn has been used as an antiepileptic remedy in Iranian TM. The scientific evaluation showed protection of mice against tonic convulsions induced byMES and PTZ treatment. The protection was more significant against PTZ induced convulsions compared to MES (Sayyah et al., 2002).

Leonotis leonurus: Aqueous extract of Leonotis leonurus L was tested for its anticonvulsant action against PTZ, picrotoxin, $\mathrm{N}$-methyl-DL11 aspartic acid and bicuculline (BIC) induced seizures. The different doses of extract showed significant delay in onset of tonic-clonic convulsions in all except BICmodel. The extract may probably act by non-specific mechanism since it affects both GABAnergic and glutamenergic system (Bienvenu et al., 2002).

Murraya koenigii: Murraya koenigii leaves are also known as curry patta and used routinely to Indian gravy and vegetarian dishes as a favorite condiment. It also reduced brain cholinesterase activity and total cholesterol levels. The 
underlying mechanism of action for the observed nootropic effect may be attributed to pro-cholinergic activity and a cholesterol lowering property (Vasudevan et al., 2009).

Moringa oleifera: The pretreatment with methanolic extract of roots of Moringa oleifera caused significant protection against strychnine (STR) and PTZ induced convulsions. The overall CNS depression along with potentiation of hypnotic activity of pentobarbitone sodium as well as diazepamis also recorded. The exact mechanism of its anticonvulsant activity is not revealed but attributed to generalized CNS depression (Gupta et al., 1999).

Mitragyna africanus: The anticonvulsant effect of Mitragyna africanus stem bark against STR induced convulsions in rats have been reported causing protection by increasing the period of onset of convulsions along with decrease in the number of episodes of spasms.

Mimosa pudica: Mimosa pudica L is a common plant in moist waste ground, lawn, open plantation and weedy thickets and traditionally claimed to be useful in many diseases related to the CNS. The anticonvulsant action of various doses of decoction of M. pudica leaves against STR and PTZ induced convulsions. The percentage of the mice protected with the test drug was $12.5 \%(500 \mathrm{mg} / \mathrm{kg})$ and $100 \%(4000 \mathrm{mg} / \mathrm{kg})$ in case of STR-model while the same doses showed $12.5 \%$ and $80 \%$ protection respectively in the PTZ model. In addition, the decoction did not show significant effect against picrotoxin induced seizures. The possible use of the drug in generalized clonic seizures in man (PTZ model) through GABAnergic neurotransmission. The inhibition of STR induced seizures highlights its indication through glycine receptors. The study revealed anticonvulsant effect of the drug through modulation of multiple neurotransmission (Ngo et al., 2004).

Myristica fragrans: The anticonvulsant activity of Myristica fragrans by using various models, animals were pretreated with various doses of the drug. In MES model, drug showed significant reduction in duration of hind limb extension and effect was dramatically reduced with increase in dose. Similar dose dependent results were obtained in PTZ model by delaying myoclonic spasm. The delayed onset of clonic convulsions were recorded in picrotoxin model while in case of lithium pilocarpine induced status epilepticus, the gradual decrease in the progression as well as severity of status epilepticus was reported with increased dose. The significant anticonvulsant activity of drug against various models of epilepsy but was unable to reveal the exact mechanism of its action. The anticonvulsant activity of the volatile oil of nutmeg, the dried seed kernel of Myristica fragrans Houtt, was using animal seizure models to evaluate its potential for acute toxicity and acute neurotoxicity. The nutmeg oil may be effective against grand mal and partial seizures, as it prevents seizure spread. Slight potentiation of clonic seizure activity limits its use for the treatment of myoclonic and absence seizures (Wahab et al., 2009).

Nylandtia spinosa: Aqueous and methanol leaf extracts of Nylandtia spinosa L. Dumont (Polygalaceae) were showed anticonvulsant activity against tonic seizures produced in mice by PTZ, Bicuclin, picrotoxin, and N-methyl-DL-aspartic acid. The relatively high LD50 of greater than $3600 \mathrm{mg} / \mathrm{kg}$ (p.o.) and $1780 \mathrm{mg} / \mathrm{kg}$ (i.p.) obtained with the aqueous extract suggest that the plant is relatively safe in mice. The phytochemical presented were tannins, saponins, reducing sugars, alkaloids, flavonoids, triterpene steroids, and cardiac glycosides in the plant material (Amabeoku, 2008).

Nerium oderum: Different extracts of Nerium oderum were screened for the anticonvulsant activity using MES and PTZ induced seizures test models. The test drug delayed the onset of convulsions (N. oderum, pet. Ether extract). In supra MES test, it was observed that the test drug (N. oderum, Pet. ether extract) produced a significant reduction in the duration of extensor phase which was reduced. Petroleum ether extract of $\mathrm{N}$. oderum showed better anticonvulsant activity as compared to other extracts (Saini et al., 2010). N. oderum commonly known as kaner (Apocynaceae) is provoked as a toxic plant but traditionally is being used to cure various ailments such as asthma, corns, cancer and epilepsy. Wide spectrums of biological activities have been reported with various constituents isolated from different parts of the plant. Two varieties are found in the plant one with the white flowers $(\mathrm{N}$. indicum) and one with the pink flowers (N. oderum). Oleandrin, a pure component from the plant has a stimulating action on the heart and also a pronounced diuretic effect. The alcoholic extract shows antibacterial activity and oil obtained from the root is used in leprosy and skin diseases. The plant is recognized in folk medicine as antidote, antibacterial, antileprotic, anticancer, cardiotonic and C.N.S. depressant (Zia et al., 1995). It is mentioned to be effective in the treatment of cancer, corns \& epilepsy and also used as C.N.S. depressant.

Nigella sativa: Thymoquinone is major constituent of Nigella sativa seeds, a TM claimed to be useful in convulsions. Anticonvulsant effect of Thymoquinone using PTZ and MESinduced seizures found that a dose of $40 \mathrm{mg} / \mathrm{kg}$ and $80 \mathrm{mg} / \mathrm{kg}$ prolong the onset of seizures and reduce the duration of myoclonic seizures induced by PTZ treatment but not by MES. The complete protective effect against mortality was reported in both the tests. In addition, flumazenil $(10 \mathrm{mg} / \mathrm{kg})$, an antagonist of benzodiazepine (GABA A-BZD receptor complex) inhibited the prolongation of seizure latency without affecting the duration of myoclonic seizures while pretreatment with different doses of naloxone $(0.1-3 \mathrm{mg} / \mathrm{kg}$ i.p) inhibited the prolongation of myoclonic seizures as well as reduced the duration of myoclonic seizures induced by thymoquinone. These results clearly suggest the effect of Thymoquinone in PTZ model probably through an opoid receptor mediated increase in GABAnergic tone (Hosseinzadeh and Parvardeh, 2004).

Nauclea latifolia: Root bark of Nauclea latifolia Smith (Rubiaceae) was exhibited anticonvulsant, anxiolytic, and sedative activity. The root bark of $\mathrm{N}$. latifolia strongly increased the total sleep time induced by diazepam. It also protected mice against MES, PTZ, and STR-induced seizures. The decoction of N. latifolia, used in TM in Cameroon in the treatment of fever, malaria, insomnia, anxiety and epilepsy and sedative (Taiwe et al., 2009).

Plumbago zeylanica: Plumbago zeylanica L. is known as white chitrak (Family: plumbaginaceae) is a perennial herb and found in most parts of India. Leaf extract were exhibited no anticonvulsant activity against PTZ and MES-induced convulsions. It was found that extract has no anticonvulsant activity. P. zeylanica is used in the traditional system of Indian medicine against a number of ailments including skin diseases, diarrhea and leprosy (Kritikar and Basu BD, 1993). P. zeylanica L. possesses antibacterial, antifungal, anticarcinogenic and radiomodifying properties (Bopaiah and Pradhan, 2001; Kavimani et al., 1996). The roots has been reported to be a powerful poison when given orally or applied to ostium uteri, causes abortion.

Portulaca oleracea: Various species of Portulaca (familyPortulacacae) are used medicinally in different countries of the world such as Jamaica, North America, Indo-China etc. The leaves of P. oleracea is claimed to cure inflammation, ulcer, urinary diseases and dysentery. Anti-convulsant activity was tested against MES and PTZ models. Abolition/reduction of 
Tonic hind limb extension and clonic convulsion was selected as anti-epileptic criteria in MES and PTZ model respectively. The aqueous extract of $P$. oleracea leaves significantly reduces the duration of tonic hind limb extension in MES. It also delays the onset and decreases the duration of clonic convulsion induced by PTZ in a dose dependent manner. The aqueous extract of P. oleracea leaves was found to have significant anticonvulsant activity (Jawaid et al., 2011).

Pimpinella anisum: Pimpinella anisum is a folk medicine in the Iranian TM. The essential oil of fruits of the plant was found to be anticonvulsant as it suppressed the tonic convulsions in mice induced by PTZ and MES. The elevation in the threshold of PTZ induced clonic convulsions is also reported.

Pimpinella anisum: Many biological actions of Pimpinella anisum L. (Ainse), including antiepileptic activity have been demonstrated. The fruit essential oil of anise affects the bioelectrical activity of snail neurons in control condition or after PTZ-induced epileptic activity. Likely candidate cellular mechanisms underlying the hyperexcitability produced by anise oil include enhancement of $\mathrm{Ca}^{2+}$ channels activity or inhibition of voltage and/or $\mathrm{Ca}^{2+}$ dependent $\mathrm{K}^{+}$channels activity (Janahmadi et al., 2008).

Petivera alliacea: Petiveria alliacea L. (tipi) a shrub from Phytolaccaceae family is popularly used in folk medicine for treating a wide variety of disorders in South and Central America. The fractions of P. alliacea L. contains biologically active substance(s) that might be acting in the CNS and have significant depressant and anticonvulsant potentials (Gomes et al., 2008).

Passiflora incarnate: The putative anxiolytic-like activity of an ethanolic extract prepared from passion flower (PF) (Passiflora incarnata L.) using the elevated plus maze (EPM) in mice. Using the EPM we were able to detect putative anxiolytic effects of a P. incarnata extract (Grundmann et al., 2009).

Rauvolfia vomitoria: Rauvolfia vomitoria (Apocynaceae) is a medicinal plant widely present all around the world, particularly in Asia and West-Africa. It is a tree that grows to a height of about $15 \mathrm{~m}$ and found in most lowland forest. The plant has been used comprehensively for various diseases. The anticonvulsant activity of R. vomitoria has also been reported.

Rubus brasiliensis: Hexanic fraction of Rubus brasiliensis prevented the PTZ induced seizures. The fraction was found to contain a benzodiazepine and hence indicated possible involvement of GABA-A receptors. This involvement is further supported by reversal of anxiolysis in rodents induced by lumozenil, a specific GABA-A benzodiazepine receptor antagonist.

Stereospermum kunthianum: Stereospermum kunthianum, Cham Sandrine Petit (Bignoniaceae) known in English as pink jacaranda is used in TM to treat an array of ailments including febrile convulsions in infants and young children by the rural dwellers in Nigeria. Although the findings study do not provide conclusive evidence, it appears that the aqueous stem bark extract of S. kunthianum produces its antiseizure effect by enhancing GABAergic neurotransmission and/or action in the brain. The aqueous extract possesses anticonvulsant activity in rodents so the shrub may be used as a natural supplementary remedy in the management, control and/or treatment of childhood convulsions (Ching et al., 2009).

Senna spectabilis: The depressant and anticonvulsant activities showed by iso-6-cassine (ISO) from Senna spectabilis (1.5 $\mathrm{mg} / \mathrm{kg}$ ) by oral route in mice and caused a significant decrease in the motor activity of animals, it reduced the remaining time of animals on Rota-rod apparatus (Silva et al., 2010).

Scrutellaria baicalensis: An effort to identify naturally occurring GABA (A) receptor benzodiazepine binding site (BDS) ligands from TM herbs, flavonoid derivatives isolated from Scutellaria baicalensis (S. baicalensis) Georgi exhibited significant affinities for the BDS. Oroxylin A selectively abolished the anxiolytic, myorelaxant and motor incoordination, but not the sedative and anticonvulsant effects elicited by diazepam, a BDS agonist. The oroxylin A is a CNS active flavonoid, and as first naturally occurring member endowed with selective antagonistic actions via the BDS (Huen et al., 2003).

Strychnos nux-vomica: The effect of detoxification on Strychnos nux-vomica seeds by traditional processing with aloe and ginger juices, by frying in cow ghee, and by boiling in cow milk was investigated. The ethanolic extracts of these samples were subjected to spontaneous motor activity, pentobarbitoneinduced hypnosis, PTZ induced convulsions, diazepam assisted protection, and morphine-induced catalepsy (Katiyar et al., 2010).

Sonchos oleraceus: Sonchus oleraceus L. has been used as a general tonic in Brazilian folk medicine. The available scientific information regarding this species is scarce, there are no reports related to its possible effect on the CNS.The extracts induce an anti-thigmotactic effect, evidenced by increased locomotor activity. The extracts administered at $30-300 \mathrm{mg} / \mathrm{kg}$, p.o. had shown anxiolytic effect (Cardoso et al., 2009).

Solanum nigrum: Solanum nigrum is in traditional medical practice, to be useful in the treatment of epilepsy in some parts of Nigeria. The anti-seizure property of the extract was potentiated by amphetamine (Wannang et al., 2008).

Scutellaria lateriflora: American skullcap (the aerial part of Scutellaria lateriflora L.) has been traditionally used by Native Americans and Europeans as a nerve tonic, sedative, and anticonvulsant. The phenolic compounds, especially flavonoids, are the predominant constituents in American skullcap; American skullcap products have similar constituents, but the content and relative proportions of the individual constituents varie widely; and American skullcap has anticonvulsant activity in rodent models of acute seizures (Zhang et al., 2009).

Searsia species: Searsia dentata and Searsia pyroides are used in TM in South African medicine to treat convulsions and epilepsy. The extracts of these plants comprise compounds that bind to the flumazenil-sensitive site on the GABA-A receptor. The extracts of S. dentata and S. pyroides inhibited the spontaneous epileptiform discharges in mouse cerebral cortical slices with ED50 of 0.62 and $1.67 \mathrm{mg}$ dry extract $/ \mathrm{mL}$, respectively (Pedersen et al., 2008).

Solanum tuberosum: Naturally occurring benzodiazepines have been identified in regular food such as wheat and potato or Solanum tuberosum, but there is still no evidence that potato extracts can affect CNS responses in vivo. The findings of the study suggest that potato juice as well as potato taken as food may have the capacity of influencing brain GABA-ergic activity (Muceniece et al., 2008).

Scutellariae radix: Aqoues extract of Scutellariae radix reported as anticonvulsant against MES induced seizures. On the other hand, it did not show any significant protection against PTZ-induced seizures. The extract had no significant effect on GABA stimulated $\mathrm{Cl}$ - uptake leaving mechanism to be revealed (Wang et al., 2000).

Valerian pavonii: Fractioning of an extract of Valeriana pavonii, a native species used in Colombian folk medicine as tranquilizer, led to the isolation and identification of isovaleramide, one of the active constituents responsible for its CNS activity as anticonvulsant. Isovaleramide is one of the active anticonvulsant constituents of $\mathrm{V}$. pavonii, for the first time reported in this species (Giraldo et al., 2010). 
Valeriana officinalis: The active principles of Valeriana officinalis and passionflower might increase the inhibitory activity of benzodiazepines binding to the GABA receptors, causing severe secondary effects (Carrasco et al., 2009).

Withania somnifera: A poly herbal extract comprising of Withania somnifera Dunal, a medicinal plant used in many neuro protective Ayurvedic medicines along with five other medicinal plants were evaluated for its protective effect against seizures induced by MES method. The uses of these medicinal plants are in the treatment of epilepsy (Balamurugan et al., 2009).

Composite preparation: Acanthus montanus, Alchornea laxiflora, Hyptis spicigera, Microglossa pyrifolia, Piliostigma reticulatum, and Voacanga africana were evaluated with respect to anticonvulsant and sedative activity using animal models (MES, N-methyl-Daspartate (NMDA), PTZ, isoniazid (INH), picrotoxin (PIC), and STR-induced convulsions or turning behavior and diazepam-induced sleep). P. reticulatum protected $62.5 \%$ to $100 \%$ of mice against convulsions and turning behavior. V. africana protected $62.5 \%$ to $87.5 \%$ of mice against convulsions and turning behavior. All of the plants except A. laxiflora also exerted sedative activity by strongly increasing the total duration of sleep induced by diazepam (Bum et al., 2009). Brahmi ghrita, one of the panchgavya formulation claimed as an anticonvulsant in Ayurveda containing Bacopa moneri (48 g), Acorus calamus (4 g), Evolvus alsinoids (4 g), Sausserea lappa and cow's ghee (80 gm). Anticonvulsant effect of various doses was tested against PTZ and MES-induced seizures in mice. The study reported the significant delay in clonic seizure induced by PTZ and dose dependent decrease in duration of hind limb extensor phase in MES model. The predicted possible mechanism of the formulation mediated through chloride channel of the GABA or benzodiazepine receptor complex, however did not reveal any firm conclusion (Achliya et al., 2005).

\section{DISCUSSION}

The most popular and widely-used animal seizure models are the traditional MES and PTZ tests. The MES test is the most frequently-used as an animal model for identification of anticonvulsant activity of drugs for the generalized (grand mal) tonic-clonic seizures (Oliveira et al., 2001). This model is based on observation of the stimulation by repeated electrical pulses induce in different neuronal structures one characteristic standard of epileptic activity (Quintans-Júnior et al., 2002). PTZ-induced seizures test is considered as an experimental model for the generalized absence seizures and also a valid model for human generalized myoclonic seizures and generalized seizures of the petitmal type. The MES test serves to identify compounds which prevent seizure spread, corresponding to generalized tonic-clonic seizures in humans. Currently-used anticonvulsant drugs (phenytoin, carbamazepines) effective in therapy of generalized tonicclonic and partial seizures have been found to show strong anticonvulsant action in MES test. Similarly, we found that treatment with PTZ-induced seizure in rats significantly reduce the duration of convulsion and delayed the onset of clonic convulsion. PTZ may cause seizures by inhibiting $\mathrm{Cl}^{+}$channels associated with GABA receptors (Ngo et al., 2001). Since PTZ has been shown to interact with the GABA neurotransmition and PTZ-induced seizures can be prevented by drugs that enhance GABAA-receptor-mediated inhibitory neurotransmission such as benzodiazepines and phenobarbital, the antagonism of PTZ-induced seizures suggests the interaction with the GABAergic neurotransmission. The effect of the EEGS in the PTZ test could therefore suggest antiepileptic efficacy against the above-mentioned seizures type in man. The MES and PTZ models are widely believed to be predictive of activity in common form of human epilepsy. All currently available AEDs those are clinically effective in the management of generalized tonic-clonic and partial seizures such as phenytoin, carbamazepine and lamotrigine etc (Rho and Sankar, 1999). They act by modulating neuronal voltage gated $\mathrm{Na}^{+}$channels (Wickenden, 2002). The bioactive constituents possess anticonvulsant acivity that may be beneficial in the management of grand mal epilepsy and lend credence to the use of the plant in the management of epilepsy in TM. Several biochemical hypothesis have been advanced involving the inhibitory GABAergic system and the system of the excitatory amino acid glutamate and aspartate. The mechanism by which PTZ is believed to exert its action is by acting as an antagonist at the GABAA receptor complex. Drugs protecting against tonic-clonic seizures induced by PTZ are considered to be useful to control myoclonic and absence seizures in humans. The antiepileptic drugs are act by delayed tonic convulsion and mortality. The benzodiazepine site in the GABAA receptor and T-type $\mathrm{Ca}^{2+}$ currents could be targets for the mechanisms of action of extract. These studies demonstrated unequivocally that like Phenytoin and possessed anticonvulsant activity. In the MES test since, inhibition of the MES test predicts the activity against generalized tonic clonic and cortical focal seizures. Hence it is suggests that the methanolic extract of the stem barks of the plant is useful in suppressing generalized tonic clonic seizures. Several drugs are thought to inhibit the seizures by regulating GABA mediated synaptic inhibition through an action at distinct sites of the synapse. Researchers are gaining new insight in to the TM in assisting the body to maintain its own self-healing systems while preventing debilitating effects of chronic diseases, like epilepsy (Ambawade et al., 2002).

A large number of drugs are available to treat various types of seizures to reduce seizure frequency and severity with an acceptable level of side effects. The ideal anti-seizure drug would suppress all seizures without causing any side effect. Unfortunately drugs used currently not only fail to control seizure in some patients, but they cause side effects. In addition safety, acceptability, competence, expenses in long term treatment, serum drug monitoring and drug interaction etc. A large number of drug interactions seen with almost all current antiepileptic drugs make it more difficult to attain easy control on seizures. An alternative system of medicine has existed in India from millennia with the objective to treat poor health with economical medicines obtained from herbs. Likewise, different regions across the globe inherit their tradition system of medicines wherein, in today's globalized era these traditional systems should not be restricted to their native origins but rather be made accessible and used throughout the human population. With this regards herbal anticonvulsants are successfully exploited (Barar, 2004; Bodhankar and Vyawahare, 2005). GABA is the major inhibitory neurotransmitter in the brain while glutamic acid is an excitatory neurotransmitter in the brain. The inhibition of GABA neurotransmitter and the enhancement of the action of glutamic acid have been shown to be the underlying factors in epilepsy. Drugs act against seizures induced by MES, PTZ, picrotoxin and NMDLA and also delayed the latency of the seizures. Antiepileptic drugs that block MES-induced tonic extension are known to act by blocking seizure spread. Moreover, drugs that inhibit voltagedependent $\mathrm{Na}^{+}$channels, such as phenytoin can prevent MESinduced tonic extension. However, phenobarbitone is as effective against electrically-induced convulsion as it is against 
PTZ induced convulsions and phenobarbitone is known to reduce the electrical activity of neurons within a chemicallyinduced epileptic focus in the cortex, while diazepam does not suppress the focal activity but prevents it from spreading. Diazepam had anticonvulsant effect on both PTZ-induced seizures and MES-induced seizures. This is consistent with the report that benzodiazepine (BDZ) agonists such as diazepam, clonazepam, etc, are more potent in the prevention of PTZinduced seizures than in that of MES-induced tonic seizures. PTZ may elicit seizures by inhibiting gabaergic mechanisms. Antiepileptic drugs, diazepam and phenobarbitone, are believed to produce their effects by enhancing GABA mediated inhibition in the brain. It is, therefore, possible that the anticonvulsant effects shown in this study by the drugs against seizures produced by PTZ might be due to the activation of GABA neurotransmission. Since the extract similarly antagonized seizures elicited by PTZ in mice, it is probable, therefore, that it may also be exerting its anticonvulsant effects by affecting gabaergic mechanisms. Picrotoxin also produced seizures in all the mice used. Picrotoxin is known to elicit seizures, by antagonizing the effect of GABA via blocking of the chloride channels linked to GABAA-receptor. The diazepam and phenobarbitone were shown to antagonize the effect of picrotoxin while the extract was also shown to delay the latency of PIC-induced seizures, suggesting that the extract may be affecting gabaergic mechanisms, probably by opening the chloride channels associated with GABA receptors. Bicuculline is a selective antagonist of GABA at the GABAAreceptors 20. The fact that the extract did not affect the seizures induced by BIC, suggests that its effect on gabaergic mechanisms may not be via the stimulation of GABAAreceptors. NMDLA was also shown to elicit seizures in all the mice used. NMDLA, a specific agonist at the NMDA receptors, mimics the action of glutamic acid and thus induces seizures by enhancing the glutaminergic system. It is not surprising that the standard drugs, diazepam and phenobarbitone, did not alter NMDLA-induced seizures to any significant extent. In this study, the extract was shown to delay the latency of seizures induced by NMDLA. It may, therefore, be exerting its anticonvulsant effect partly by affecting glutaminergic mechanisms. Based on the present state of knowledge of the chemical constituents of the extract, it is not possible to attribute with certainty its anticonvulsant effect to one or several active principles among those detected in the screening. However, triterpenic steroids and triterpenoidal saponins are reported to possess anticonvulsant activity in some experimental seizure models such as MES and PTZ. Some alkaloids, monoterpenes, flavonoids also have protective effects against PTZ, PIC and NMDLA-induced convulsions. It is worthwhile to isolate the bioactive principles, which are responsible for these activities; the process has commenced in our laboratory. These findings justify the traditional use of this plant in the control and/or treatment of convulsions and epilepsy (Birbeck et al., 2007; Bialer, 2006; Bialer et al., 2004; Chisholm, 2005; Dwivedi, 2001; French et al., 1999; Fisher et al., 2005; Huguenard, 1999; Kwan and Brodie, 2000; Mohanraj and Brodie, 2003; Rogawski and Loscher, 2004; Wagh et al., 2011).

A significant reduction in the time required for the recovery (righting reflex) was observed in this study, which proves that PHE was providing a beneficial effect in controlling MES induced seizures. The administration of PHE significantly increased the brain levels of serotonin, dopamine and noradrenaline, which could be attributed to the significant protection offered against MES induced seizures. The increase in the brain monoamine level by inhibiting the MAO, an enzyme responsible for destruction of biogenic amines tends to raise the seizure threshold. Serotonin (5-Hydroxy tryptamine) is an inhibitory neuro-transmitter involved in the regulation of mood, sleep, anxiety, arousal and aggression. Serotonin agonists, precursors and neuronal uptake inhibitors are reported to enhance narcoleptic catalepsy. The increase in the serotonergic transmission raises the threshold of PTZ induced seizures in many animal test systems, thereby protecting against PTZ induced convulsions. Dopamine activation seems to be crucial with respect to a lasting internal encoding of motor skills. Dopamine is also believed to provide a teaching signal to parts of brain responsible for acquiring new behavior. In insects, a similar effect has been demonstrated with respect to octopamine, a chemical relative of dopamine. These effects are mediated by dopminergic receptors situated in several parts of brain including substantia nigra. Noradrenaline has also a role to play in the control of seizures, but less significantly when compared with other biogenic amines, as it is mainly concerned with BP regulation. It has a potential for biphasic effect of glutamate in the cerebellum and would inhibit glutamate release at low concentrations. Over activation of glutamate receptors may lead to delayed neuro degeneration as a result of increased influx of calcium ions into neurons. The well-established drugs like phenytoin, carbamazepine and benzodiazepines exerts their action by inhibiting $\mathrm{Ca}^{2+}$ calmodulin stimulated protein phosphorylation in presynaptic nerve terminal. A low concentration of dopamine in cerebellum also has an inhibitory effect on glutamate. Inhibition of prostaglandin synthesis is reported to increase the brain levels of dopamine and noradrenaline, which also causes an inhibition of seizure activity (Balamurugan et al., 2009).

\section{CONCLUSION}

There is an increasing interest in the health risks related to the use of herbal remedies. Although most consumers think that phytomedicines are safe and without side effects, interactions between complementary alternative and conventional medicines are being described. Due to the increase in herbal product self-medication, the use of herbal remedies should be registered while taking the personal clinical history. With the introduction of allopathic drugs, the use of crude drugs from medicinal plants is on the decline and subsequently this traditional knowledge may be lost in the near future. Many drugs that increase the brain content of GABA have exhibited anti-convulsant activity against seizure induced by MES, PTZ and lithium Pilocarpine. The MES is probably the best validated method for assessment of anti-epileptic drugs in generalized tonic clonic seizures. The present allopathic pharmacotherapy in the management of epilepsy is based upon the nature and type of epilepsy. It is reported that about $30 \%$ of patients require polytherapy for better control, which in turn increases the chances of drug-drug interaction and side effects. The reports of possible mechanism of action have shown that the identification of particular fraction and or active constituent can further providemore extensive results. Comparatively lesser side effects and interactions associated with these herbal remedies can make the anticonvulsant treatment more rationale and patient friendly. The review also found that certain herbal drugs mentioned in various TM across the globe have not been exploited up to the desired level, and these claims could be a better target for the development of more and more alternatives to allopathic anticonvulsants. 


\section{ACKNOWLEDGEMENTS}

The authors extend their sincere thanks to Department of Pharmacy, GRD(PG)IMT, Dehradun, India, for providing assistance for the preparation of this manuscript.Acknowledge Acknowledge Acknowledge Acknowledge

\section{CONFLICT OF INTEREST}

Nil

\section{REFERENCES}

Achliya GS, Wadodkar SG, Dorle AK. Evaluation of sedative and anticonvulsant activities of Unmadnashak ghrita. J Ethnopharmacol. 2004;94:77-83.

Achliya GS, Wadodkar SG, Dorley AK. Evaluation of CNS activity of Bramhi Ghrita. Ind J Pharmacol. 2005;37:33-36.

Amabeoku GJ, Anticonvulsant activity of Nylandtia spinosa L. Dumont (Polygalaceae) aqueous and methanol leaf extracts in mice. Hum Exp Toxicol. 2008;27:811-818.

Ambawade SD, Kasture VS, Kasture SB. Anticonvulsant activity of roots and rhizomes of Glycyrrhiza glabra. Indian J Pharmacol. 2002;34:251-255.

Amos S, Kolawole E, Akah P, Wambebe C, Gamaniel K. Behavioral effects of the aqueous extract of Guiera senegalensis in mice and rats. Phytomedicine. 2001;8:356-361.

Arumugam S, Palanivelu A, Retnasamy G, Ramaiyan D. Study on the Antiseizure Activities of Inner Bark of Guettarda Speciosa (L.). Iranian J Pharmacol Ther. 2009;8:73-76.

Bagheri SM, Sahebkar A, Gohari AR, Saeidnia S, Malmir M, Iranshahi M, Evaluation of cytotoxicity and anticonvulsant activity of some Iranian medicinal Ferula species. Pharm Biol. 2010;48:242-246

Balakrishnan S, Pandhi P, Bhargava VK. Effect of nimodipine on the efficacy of commonly used antiepileptic drugs in rats. Ind J Exp Biol. 1998;36:51-54.

Balamurugan G, Muralidharan P, Selvarajan S. Anti Epileptic Activity of Poly Herbal Extract from Indian Medicinal Plants. J Sci Res. 2009;1;153-159.

Barar FSK. Essentials of Pharmacotheraputics. (Newdelhi, India: Chand and Company Ltd. Publishers), 2000.

Bharal N, Sahaya K, Jain S, Mediratta PK, Sharma KK, Curcumin has anticonvulsant activity on increasing current electroshock seizures in mice. Phytother Res. 2008;22:16601664 .

Bialer M, Johannessen SI, Kupferberg HJ, Levy RH, Perucca E, Tomson T. Progress report on new antiepileptic drugs: a summary of the Seventh Eilat Conference (EILAT VII). Epilepsy Res. 2004;61:1-48.

Bialer M. New antiepileptic drugs that are second generation to existing antiepileptic drugs. Expert Opin Investig Drugs.

\section{6;15:637-647.}

Bienvenu E, Amabeoku GJ, Eagles PK, Scott G, Springfield EP. Anticonvulsant activity of aqueous extract of Leonotis leonurus. Phytomedicine. 2002;9:217-223.

Birbeck G, Chomba E, Atadzhanov M, Mbewe E, Haworth A. The social and economic impact of epilepsy in Zambia: a crosssectional study. Lancet Neurol. 2007;6:39-44.

Bodhankar SL, Vyawahare NS. A Text book of Pathophysiology. (Pune, India: Nirali Prakashan), 2005.

Bopaiah CP, Pradhan N. Central nervous system stimulatory action from the root extract of Plumbago zeylanica in rats. Phytother Res. 2001;15:153-156.

Bum EN, Taiwe GS, Nkainsa LA, Moto FC, Seke Etet PF, Hiana IR, Bailabar T, Rouyatou, Seyni P, Rakotonirina A, Rakotonirina SV, Validation of anticonvulsant and sedative activity of six medicinal plants. Epilepsy Behav. 2009;14:454458.

Bum EN, Schmutz M, Meyer C, Rakotonirina A, Bopelet M, Portet C, Jeker A, Rakotonirina SV, Olpe HR, Herrling P. Anticonvulsant properties of the methanolic extract of Cyperus articulatus (Cyperaceae). J Ethnopharmacol. 2001;76:145-150.

Bum EN, Dawack DL, Schmutz M, Rakotonirina A, Rakotonirina SV, Portet C, Jeker A, Olpe HR, Herrling P. Anticonvulsant activity of Mimosa pudica decoction. Fitoterapia. 2004;75:309-314.

Burkill HM. The Useful Plants of West Tropical Africa. $2^{\text {nd }}$ ed. (Kew, UK: Royal Botanical Garden), pp. 26-30, 2000.

Cambie RC, Ash J. Fijian Medicinal Plants. (Clayton South VIC, Australia: CSIRO), p. 255, 1994.

Cardoso Vilela F, Soncini R, Giusti-Paiva A. Anxiolytic-like effect of Sonchus oleraceus L. in mice. J Ethnopharmacol. 2009;124;325-327.

Carrasco MC, Vallejo JR, Pardo-de-Santayana M, Peral D, Martín MA, Altimiras J, Interactions of Valeriana officinalis L. and Passiflora incarnata L. in a patient treated with lorazepam. Phytother Res. 2009;23:1795-1796.

Chao JY, Baik KU, Jung JH, Park MH. In vitro antiinflammatory effects of cynaropicrin, a sesquiterpene lactone, from Sassurea lappa. Eur J Pharmacol. 2000;398:399407.

Ching FP, Omogbai EK, Otokiti IO, Aqueous stem bark extract of Stereospermum kunthianum (Cham, Sandrine Petit) protects against generalized seizures in pentylenetetrazole and electroconvulsive models in rodents. Afr J Tradit Complement Altern Med. 2009;6:544-548.

Chisholm D. Cost-effectiveness of first-line antiepileptic drug treatments in the developing world: a population-level analysis. Epilepsia. 2005;46:751-759.

Chitme HR, Chandra M, Kaushik S. Studies on anti-diarrhoeal activity of calotropis gigantea r.br. in experimental animals. J Pharm Pharm Sci. 2004; 7:70-75. 
Chopra RN, Nayar SL, Chopra IC. Glossary of Indian Medicinal Plants. $1^{\text {st }}$ ed. (New Delhi, India: National Institute of Science Communication), pp. 85-126, 1996.

Cockerell OC, Johnson AL, Sander JW, Hart YM, Shorvon SD. Remission of epilepsy: results from the National general Practice study of epilepsy. Lancet. 1995;346:140-144.

Council of Scientific \& Industrial Research. The Wealth of India - A Dictionary of Indian Raw materials and Industrial products, Vol. 10. (New Delhi, India: CSIR), pp. 581-585, 1995.

Curio M, Jacone H, Perrut J, Pinto AC, Filho VF, Silva RC, Acute effect of Copaifera reticulata Ducke copaiba oil in rats tested in the elevated plus-maze: an ethological analysis. J Pharm Pharmacol. 2009;61:1105-1110.

Debnath S, Kannadasan M, Ghosh S, Ghosh NS, Chakraborty R, Sen S. Antiepileptic activity of the hydroalcoholic extract of Erythrina fusca Lour. bark against the animal models of MES, PTX and PTZ induced epileptic seizure models. Int J Chem Res. 2010;1:6-10.

Devinsky O. Cognitive and behavioral effects of antiepileptic drugs. Epilepsia. 1995;36:S46-S65.

Dwivedi C. Antiepileptic Drugs. Am J Pharm Educ. 2001;65:197-202.

Fisher RS, van Emde Boas W, Blume W, Elger C, Genton P, Lee P, Engel J Jr. Epileptic seizures and epilepsy: Definitions proposed by the international league against epilepsy (ilae) and the international bureau for epilepsy (ibe). Epilepsia. 2005;46:470-472.

French J, Smith M, Faught E, Brown L. Practice advisory: The use of felbamate in the treatment of patients with intractable epilepsy: Report of the Quality Standards Subcommittee of the American Academy of Neurology and the American Epilepsy Society. Neurology. 1999;52:1540-1545.

French JA, Kanner AM, Bautista J, Abou-Khalil B, Browne T, Harden CL, Theodore WH, Bazil C, Stern J, Schachter SC, Bergen D, Hirtz D, Montouris GD, Nespeca M, Gidal B, Marks WJ Jr, Turk WR, Fischer JH, Bourgeois B, Wilner A, Faught RE Jr, Sachdeo RC, Beydoun A, Glauser, TA. Efficacy and tolerability of the new antiepileptic drugs i: Treatment of new onset epilepsy: Report of the therapeutics and technology assessment subcommittee and quality standards subcommittee of the american academy of neurology and the american epilepsy society. Epilepsia. 2004;5:401-409.

Fulzele SV, Bhurchandi PM, Kanoje VM, Joshi SB, Dorle AK. Immunostimulant activity of Ashtamangal ghrita in rats. Indian J Pharmacol. 2002;34:194-197.

Gerlach AC, Krajewski JL. Antiepileptic Drug Discovery and Development: What Have We Learned and Where Are We Going?. Pharmaceuticals. 2010;3:2884-2899.

Gilani AH, Aziz N, Khan MA, Shaheen F, Jabeen Q, Siddiqui BS, Herzig JW. Ethnopharmacological evaluation of the anticonvulsant, sedative and antispasmodic activities of Lavandula stoechas L. J Ethnopharmacol. 2000;71:161-167.

Giraldo SE, Rincón J, Puebla P, Marder M, Wasowski C, Vergel
$\mathrm{N}$, Guerrero MF, Isovaleramide, an anticonvulsant molecule isolated from Valeriana pavonii. Biomedica. 2010;30:245-250.

Gomes PB, Noronha EC, de Melo CT, Bezerra JN, Neto MA, Lino CS, Vasconcelos SM, Viana GS, de Sousa FC, Central effects of isolated fractions from the root of Petiveria alliacea $\mathrm{L}$. (tipi) in mice. J Ethnopharmacol. 2008;120:209-214.

González-Trujano ME, López-Meraz L, Reyes-Ramírez A, Aguillón M, Martínez A, Effect of repeated administration of Annona diversifolia Saff.(ilama) extracts and palmitone on rat amygdala kindling. Epilepsy Behav. 2009;16:590-595.

Goyal M, Nagori BP, Sasmal D, Sedative and anticonvulsant effects of an alcoholic extract of Capparis deciduas. J Nat Med. 2009;63:375-379.

Grundmann O, Nakajima J, Kamata K, Seo S, Butterweck V, Kaempferol from the leaves of Apocynum venetum possesses anxiolytic activities in the elevated plus maze test in mice. Phytomedicine. 2009;16:295-302.

Gupta M, Muzumdar UK, Chakrabrati S. CNS activities of methanolic extract of Moringa oleifera root in mice. Fitoterapia. 1999;70:244-250.

Gupta YK, Sharma M, Chaudhary G. Antiepileptic activity of Panax ginseng against pentylenetetrazole induced kindling in rats. Indian J Physiol Pharmacol. 2001;45:502-506.

Hauser WA, Annegers JF, Kurland LT. Prevalence of epilepsy in Rochester, Minnesota: 1940-1980. Epilepsia. 1991;32:429445

Hauser WA, Annegers JF. Epidemiology of Epilepsy. In Textbook of Epilepsy. (Edinburgh, UK: Churchill Livingstone), pp. 23-45, 1993.

Holmes GL. Critical issues in the treatment of epilepsy. Am J Hosp Pharm. 1993;50:S5-S16.

Hosseinzadeh H, Karimi GR, Rakhshanizadeh M. Anticonvulsant effect of Hypericum perforatum: role of nitric oxide. J Ethnopharmacol. 2005;98:207-208.

Hosseinzadeh H, Parvardeh S. Anticonvulsant effects of thymoquinone, the major constituent of Nigella sativa seeds, in mice. Phytomedicine. 2004;11:56-64.

Abe K, Saito H. Effects of saffron extract and its constituent crocin on learning behaviour and long-term potentiation. Phytother Res. 2000;14:149-152.

Huen MS, Leung JW, Ng W, Lui WS, Chan MN, Wong JT, Xue H. 5,7-Dihydroxy-6-methoxyflavone, a benzodiazepine site ligand isolated from Scutellaria baicalensis Georgi, with selective antagonistic properties. Biochem Pharmacol. 2003;66:125-132.

Huguenard JR. Neuronal circuitry of thalamocortical epilepsy and mechanisms of antiabsence drug action. Adv Neurol. 1999;79:991-1000.

Janahmadi M, Farajnia S, Vatanparast J, Abbasipour H, Kamalinejad M. The fruit essential oil of Pimpinella anisum L.(Umblliferae) induces neuronal hyperexcitability in snail 
partly through attenuation of after-hyperpolarization. J Ethnopharmacol. 2008;120:360-365.

Jawaid T, Argal S, Singh S. Botanicals and herbs: A traditional approach in treatment of epilepsy. J Pharm Res. 2011;4:11381140 .

Kabir M, Iliyasu Z, Abubakar IS, Kabir ZS, Farinyaro AU. Knowledge. Attitude and Beliefs about epilepsy among adults in a northern Nigerian urban community. Annals Afr Med. 2005;4:107-112.

Kasture VS, Kasture SB, Chopde CT. Anticonvulsive activity of Butea monosperma flowers in laboratory animals. Pharmacol Biochem Behav. 2002;72:965-972.

Katiyar C, Kumar A, Bhattacharya SK, Singh RS. Ayurvedic processed seeds of Nuxvomica: neuropharmacological and chemical evaluation. Fitoterapia. 2010;81:190-195.

Kavimani S, Iiango R, Madheswaran M, Jayakar B, Gupta M, Majumdar UK. Antitumor activity of plumbagin against dalton's ascitic lymphoma.2 Indian J Pharm Sci. 1996;58:194196.

Kirtikar KR, Basu BD. Indian Medicinal Plants. (Allahabad, India: Lalit Mohan Basu), pp. 1546-1549, 2003.

Kirtikar KR, Basu BD. Indian Medicinal Plants. Vol. 3. (Dehradun, India: International Book Distributors), 1998.

Kritikar KR, Basu BD. Indian Med Plants. Vol. 2. (Dehradun, India: Shiva Publishers), 1993.

Kulkarni S, Desai S. Immunostimulant activity of inulin isolated from Saussurea lappa roots. Indian J Pharm Sci. 2001;63:292-294.

Maiha BB, Magaji MG, Yaro AH, Hamza AH, Ahmed ST and Magaji RA. Anticonvulsant Studies on Cochlospermum Tinctorium and Paullinia Pinnata Extracts in Laboratory Animals. Nig J Pharm Sci. 2009;8:102-108.

Mattson RH. Efficacy and adverse effects of established and new antiepileptic drugs. Epilepsia. 1995;36:S13-S26.

Miwa H, Iijima M, Tanaka S, Mizuno Y. Generalized convulsions after consuming a large amount of Gingko nuts. Epilepsia. 2001;42:280-281.

Mohanraj R, Brodie MJ. Measuring the efficacy of antiepileptic drugs. Seizure. 2003;12:413-443.

Muceniece R, Saleniece K, Krigere L, Rumaks J, Dzirkale Z, Mezhapuke R, Kviesis J, Mekss P, Klusa V, Schiöth HB, Dambrova M. Potato (Solanum tuberosum) juice exerts an anticonvulsant effect in mice through binding to GABA receptors. Planta Med. 2008;74:491-496.

Mishra N, Oraon A, Dev A, Jayaprakash V, Basu A, Pattnaik AK, Tripapthi SN, Akhtar M, Ahmad S, Swaroop S, Basu M. Anticonvulsant activity of Benkara malabarica (Linn.) root extract: In vitro and in vivo investigation. J Ethnopharmacol. 2010;128;533-536.
Nqo Bum E, Taiwe GS, Moto FC, Ngoupaye GT, Nkantchoua GC, Pelanken MM, Rakotonirina SV, Rakotonirina A. Anticonvulsant, anxiolytic, and sedative properties of the roots of Nauclea latifolia Smith in mice. Epilepsy Behav. 2009; $15: 434-440$.

Okokon JE, Nwafor PA, Antiulcer and anticonvulsant activity of Croton zambesicus. Pak J Pharm Sci. 2009;22;384-390.

Oliveira FA, de Almeida RN, Sousa MF, Barbosa-Filho JM, Diniz SA, Medeiros IA. Anticonvulsant properties of $\mathrm{N}$ salicyloyltryptamine in mice. Pharmacol Biochem Behav. 2001;68:199-202.

Pal D, Dutta S, Sarkar A. Evaluation of CNS activities of ethanol extract of roots and rhizomes of Cyperus rotundus in mice. Acta Pol Pharm. 2009;66:535-541.

Pedersen ME, Vestergaard HT, Stafford GI, van Staden J, Jäger AK. The effect of extracts of Searsia species on epileptiform activity in slices of the mouse cerebral cortex. J Ethnopharmacol. 2008;119:538-541.

Raza M, Shaheen F, Choudhary MI, Sambati S, Rafig A, Suria A, Atta-ur-Rahman, DeLorenzo, R J. Anticonvulsant activities of ethanolic extract and aqueous fraction isolated from Delphinium denudatum. J. Ethnopharmacol. 2001;78:73-78.

Reddy J, Gnanasekaran D, Vijay D, Ranganathan TV. In vitro studies on anti asthmatic, analgesic and anti convulsant activities of the medicinal plant Bryonia laciniosa.Linn. Inter $\mathbf{J}$ Drug Disc. 2010;2:1-10.

Reza HM , Mohammad H, Golnaz E, Gholamreza S, Effect of methanolic extract of Hyoscymus niger L. on the seizure induced by picritoxin in mice. Pak J Pharm Sci. 2009;22:308312.

Rho JM, Sankar R. The pharmacologic basis of antiepileptic drug action. Epilepsia. 1999;40:1471-1483.

Ribeiro RA, Leite JR. Nantenine alkaloid presents anticonvulsant effect on two classical animal models. Phytomedicine. 2003;10:563-568.

Rogawski MA, Löscher W. The neurobiology of antiepileptic drugs. Nat Rev Neurosci. 2004;5:553-564.

Saini P, Kannapan N, Diwan A, Kumar P, Antil V, Sharma S, Singh S. Anticonvulsant activity of flower part of N. oderum. IJPBS. 2010;1:1-4.

Sayyah M, Mandgary A, Kamalinejad M. Evaluation of the anticonvulsant activity of the seed acetone extract of Ferula gummosa Boiss. against seizures induced by pentylenetetrazole and electroconvulsive shock in mice. J Ethnopharmacol. 2002;82:105-109.

Sayyah M, Valizadeh J, Kamalinejad M. Anticonvulsant activity of the leaf essential oil of Laurus nobilis against pentylenetetrazole- and maximal electroshock-induced seizures Phytomedicine. 2002;9:212-216.

Silva FO, Silva MG, Feng D, de Freitas RM. Evaluation of central nervous system effects of iso-6-cassine isolated from Senna spectabilis var. excelsa (Schrad) in mice. Fitoterapia. 


\section{1;82:255-259.}

Silva MR, Ximenes RM, da Costa JG, Leal LK, de Lopes AA, Viana GS, Comparative anticonvulsant activities of the essential oils (EOs) from Cymbopogon winterianus Jowitt and Cymbopogon citratus (DC) Stapf. in mice. Nau Schr Arch Pharm. 2010;381:415-426.

Singh D, Goel RK. Anticonvulsant effect of Ficus religiosa: role of serotonergic pathways. $\mathrm{J}$ Ethnopharmacol. 2009;123:330-334.

Smith MC, Bleck TP. Convulsive Disorders: toxicity of anticonvulsants. Clin Neuropharmacol. 1991;14:97-115.

Sridharan, R. Epidemiology of epilepsy. Current Science. 2002;82:664-670.

Sumathy T, Subramanian S, Govindaswamy S, Balakrishna K, Veluchamy G. Protective role of Bacopa monniera on morphine induced hepatotoxicity in rats. Phytother Res. 2001;15:643-645.

Umukoro S, Aladeokin AC. Evaluation of the anti-stress and anticonvulsant activities of leaf extract of Alchornea cordifolia in mice. J Ethnopharmacol. 2010;127:768-770.

Vasudevan M, Parle M. Antiamnesic potential of Murraya koenigii leaves. Phytother Res. 2009;23:308-316.

Visweswari G, Prasad KS, Chetan PS, Lokanatha V, Rajendra W. Evaluation of the anticonvulsant effect of Centella asiatica (gotu kola) in pentylenetetrazol-induced seizures with respect to cholinergic neurotransmission. Epilepsy Behav. 2010;17:332-335.

Vyawahare NS, Bodhankar SL, Anticonvulsant Activity of Argyreia speciosa in Mice. Indian J Pharm Sci. 2009;71:131134.

Wagh RV, Antre RV, Oswal RJ, Nimje HM. Anticonvulsant Activity: An Overview. JPSBR. 2011;1:142-147.

Wahab A, UI Haq R, Ahmed A, Khan RA, Raza M. Anticonvulsant activities of nutmeg oil of Myristica fragrans. Phytother Res. 2009;23:153-158.

Wang HH, Liao JF, Chen CF. Anticonvulsant effect of water extract of Scutellariae radix in mice. J Ethnopharmacol. 2000;73:185-190.

Wannang NN, Anuka JA, Kwanashie HO, Gyang SS, Auta A. Anti-seizure activity of the aqueous leaf extract of Solanum nigrum linn (solanaceae) in experimental animals. Afr Health Sci. 2008;8:74-79.

WHO. Epilepsy: aetiology, epidemiology and prognosis. Fact sheet No 165. Available at: http://www.who.int/mediacentre /factsheets/ fs 165/en/ (accessed on $01^{\text {st }}$ April 2013)

Wickenden AD. Potassium channels as antiepileptic drug targets. Neuropharmacol. 2002;43:1055-1060.

Ya'u J, Yaro AH, Abubakar MS, Anuka JA, Hussaini IM. Anticonvulsant activity of Carissa edulis (Vahl) (Apocynaceae) root bark extract. J Ethnopharmacol. 2008;120:255-258.
Yemitan OK, Adeyemi OO. CNS depressant activity of Lecaniodiscus cupanioides. Fitoterapia. 2005;76:412-418.

Zhang Z, Lian XY, Li S, Stringer JL, Characterization of chemical ingredients and anticonvulsant activity of American skullcap (Scutellaria lateriflora). Phytomedicine. 2009;16:485493.

Zia A, Siddqui S, Begum S, Siddiqui S, Suria A. Studies on the constituents of the leaves of Nerium oleander on behavior pattern in mice. J Ethnopharmacol. 1995;49:33-39. 